\title{
Congenitally corrected transposition of the great arteries in an 80 year old woman
}

\author{
M Roffi, S F de Marchi, C Seiler
}

\begin{abstract}
Congenitally corrected transposition of the great arteries (CCTGA) is a rare form of congenital heart disease characterised by atrioventricular as well as ventriculoarterial discordance. It is usually associated with a variety of severe intracardiac defects. Few patients with this abnormality survive past 50 years. An 80 year old woman was admitted to the hospital because of mild congestive heart failure. Cardiac examination revealed a 4/6 holosystolic and a $2 / 6$ decrescendo diastolic murmur at the left sternal border. Radiography, echocardiography, and computed tomography confirmed newly diagnosed CCTGA without associated intracardiac defects.

(Heart 1998;79:622-623)
\end{abstract}

Keywords: corrected transposition of the great arteries; adult congenital heart disease; natural history; congenital heart disease

Congenitally corrected transposition of the great arteries (CCTGA) is a rare form of congenital heart disease first described by Von Rokitansky in $1875^{1}$ and characterised by atrioventricular and ventriculoarterial discordance. The atrioventricular discordance implies that the morphological right atrium drains into the morphological left ventricle (LV), and the morphological left atrium into the morphological right ventricle (RV). Thus, the LV supplies the pulmonary circulation, and the RV supports the systemic circulation. CCTGA accounts for less than $1 \%$ of congenital heart disease cases, and is usually associated with a severely reduced life expectancy owing to ventricular septal defects $(74 \%)$, pulmonary valvar stenosis $(74 \%)$, systemic (tricuspid) valve abnormalities (38\%), and complete heart block $(5 \%) .^{2}$ Only $1-10 \%$ of individuals with CCTGA have no associated defects. ${ }^{3-6}$ Their life expectancy is limited by the onset of systemic (morphologically right) ventricular failure in their 40 s or 50 s.

\section{Case report}

An 80 year old woman was admitted to the hospital because of mild congestive heart failure. Cardiac examination revealed a $4 / 6$ holosystolic and a 2/6 decrescendo diastolic murmur at the left sternal border. Chest radiography revealed an absent pulmonary artery segment, a prominent right pulmonary hilus, and an enlarged cardiac silhouette (fig 1).

Echocardiography showed the aorta to arise from the morphological RV, which was identified by the three leaflet tricuspid valve that inserted more apically than the mitral valve (fig 2 ). The pulmonary trunk, identified by its bifurcation, arose from the morphological LV. The systemic ventricle (RV) was dilated, the walls measured $10 \mathrm{~mm}$, and the systolic RV function was severely reduced (ejection fraction $30 \%$ ). There was moderate atrioventricular (tricuspid) valve regurgitation. The pulmonic ventricle (LV) showed normal function and there was a mild atrioventricular (mitral) valve regurgitation. There was a moderate aortic regurgitation but no pulmonary valvar stenosis. No intracardiac shunts were found. The systolic pulmonary pressure was $55 \mathrm{~mm} \mathrm{Hg}$. Computed tomography of the chest, performed one year earlier, demonstrated that the calcified aorta was situated anteriorly and to the left of the pulmonary trunk, and that the two vessels ran in parallel (fig 3). The patient was given angiotensin converting enzyme inhibitors and diuretics; she improved and could be discharged.

\section{Discussion}

Patients with CCTGA rarely survive to old age. Our patient is noteworthy for several reasons.

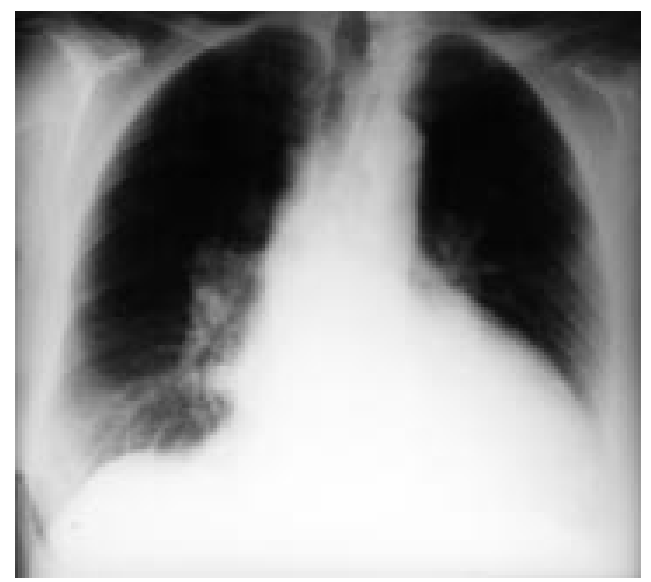

Figure 1 Chest radiograph showing an enlarged cardiac silhouette, a prominent right hilus, and absence of a pulmonary artery segment. 


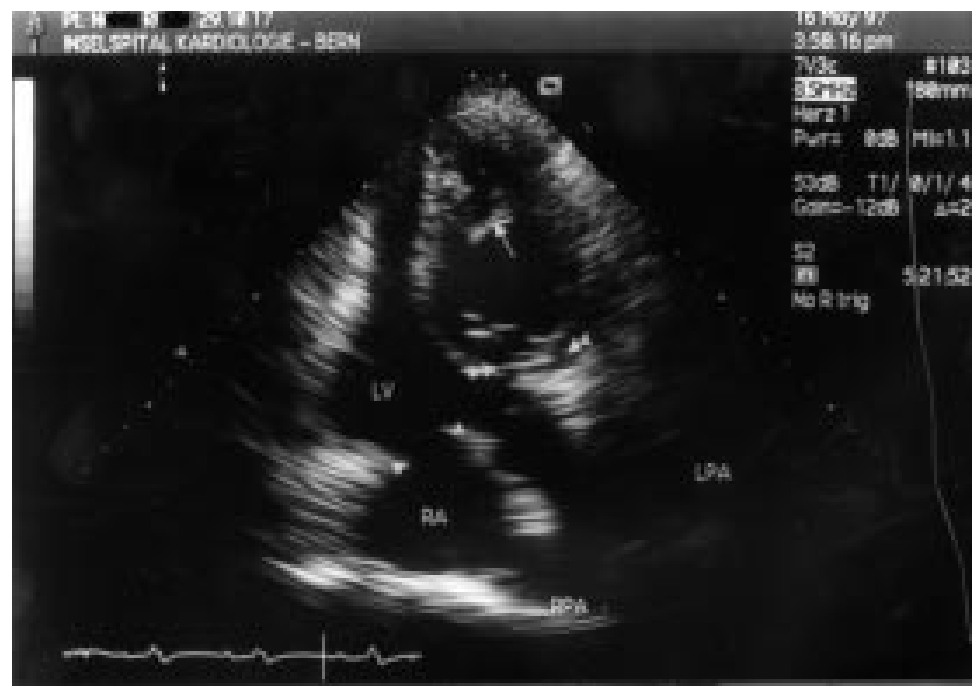

Figure 2 Apical view showing a topographically left sided right ventricle with the crista interventricularis (arrow), heavy trabeculations, and a tricuspid valve (double arrowheads), which is located more apically than the mitral valve (single arrowheads). The left ventricle $(L V)$ supplies the pulmonary artery, identified by its bifurcation into a right $(R P A)$ and left pulmonary artery (LPA). RA, right atrium.



Figure 3 Spiral computed tomography of the chest showing a calcified ascending aorta (single arrowhead) located anteriorly and to the left of the main pulmonary artery (double arrowheads). In addition, the proximal segments of the two vessels run in parallel. Arrow points to descending aorta.
CCTGA without associated intracardiac defects is very rare. Fewer than 30 patients older than 40 years have been reported in the literature. ${ }^{2-9}$ Our patient's survival, together with two other cases is the longest ever described. ${ }^{8} 9$

Much controversy exists regarding the ability of the morphological RV to support the systemic circulation. ${ }^{27}$ In patients with CCTGA, who present as a naturally occurring model of this adaptation, systemic ventricular failure is the cause of death in more than $50 \% .^{2}$ A progressive deterioration of the systolic function of the systemic ventricle has also been described in patients without associated cardiac defects. Complete heart block and increasing left (tricuspid) atrioventricular valve regurgitation are known contributing factors. Our patient presented with a profound deterioration in systemic ventricular systolic function. As there is no evidence for severe concomitant heart disease, the deterioration in systemic ventricular function may either be caused by long term maladaptation of the geometrically unfavourable RV shape or to the inability of the right coronary artery to supply the hypertrophied RV. Surprisingly, the limits of the RV adaptation to the systemic afterload seemed to be reached only at the age of 80 years.

1 Von Rokitansky K. Die Defekte der Scheidewände des Herzens. Pathologisch-anatomische Abhandlung. Wien: Wilhelm Braumüller, 1875.

2 Connelly MS, Liu PP, Williams WG, et al. Congenitally corrected transposition of the great arteries in the adult: functional status and complications. $\mathcal{F}$ Am Coll Cardiol 1996;27: 1238-43.

3 Ikeda U, Furuse $\mathrm{M}$, Suzuki $\mathrm{O}$, et al. Long-term survival in aged patients with corrected transposition of the great arteries. Chest 1992;101:1382-5.

4 Bjarke BB, Kidd BS. Congenitally corrected transposition of the great arteries. A clinical study of 101 cases. Acta Paedithe great arteries. A clinical

5 Allwork SP, Bentall HH, Becker AE, et al. Congenitally corrected transposition of the great arteries: morphologic study of 32 cases. Am f Cardiol 1976;38:910-23.

6 Lundstrom U, Bull C, Wyse RK, et al. The natural and "unnatural" history of congenitally corrected transposition. Am f Cardiol 1990;65:1222-9.

7 Presbitero P, Somerville J, Rabajoli F, et al. Corrected transposition of the great arteries without associated defects in adult patients: clinical profile and follow up. Br Heart $\mathcal{F}$ 1995;74:57-9.

8 Attie F, Rijlaarsdam M, Zabal C, et al. Corrected transposition of the great arteries in patients over 65 [in Spanish]. Arch Inst Cardiol Mex 1995;65:57-64.

9 Pezard P, Banus Y, Laporte J, et al. Corrected transposition of the great vessels in aged adults. Apropos of 2 patients aged 72 and 80 [in French]. Arch Mal Coeur Vaiss 1986;79: $1637-42$. 